\title{
Venous Thromboembolism in Hospitalized Melanoma Patients: Analysis from the National Inpatient Sample Database
}

\author{
Hussam Alhasson' \\ Kadhim Al-banaa ${ }^{2}$ \\ Mohammad Abu-Tineh (iD ${ }^{3}$ \\ Bassam Alhasson ${ }^{4}$ \\ Yu Zhao' \\ Mohamed A Yassin ${ }^{3}$ \\ 'Department of Medicine, Rochester \\ Regional Health, Rochester, NY, USA; \\ ${ }^{2}$ Department of Hematology, University \\ of California-San Diego, San Diego, CA, \\ USA; ${ }^{3}$ National Center for Cancer Care \\ and Research, Hamad Medical \\ Corporation, Doha, Qatar; ${ }^{4}$ Clinical \\ Trials Center of Middle Tennessee, \\ Franklin, Tennessee, USA
}

Introduction: The association between cancer and hyper-coagulability is well known. However, the association between melanoma and venous thromboembolism (VTE) has not been identified.

Methods: We studied the national inpatient sample (NIS) which compromise $20 \%$ of US hospitalization to better characterize melanoma and VTE. We analyzed the data between 2010 and 2014 using ICD-9 codes.

Results: Melanoma patients were grouped into presence/absence of VTE. Multiple logistic regression was used to obtain the odds ratio (OR) to compare the mortality of the inpatient, total charges, length of stay (LOS), and disability at discharge. A total of 61,812 melanoma patients were identified, of which $5.2 \%$ were hospitalized for VTE. The presence of VTE was associated with a remarkable higher rate of discharge with a moderate to severe disability $(57.5 \%$ vs $41.4 \%, \mathrm{P}<0.001)$, in-hospital stroke (7.6\% vs $4.9 \%, \mathrm{P}<0.001)$, and inhospital mortality $(8.8 \%$ vs $5.1 \%, \mathrm{P}<0.001)$. Costs of hospitalization $(64,720 \$$ vs 46,606 , $\mathrm{P}<0.001$ ) and LOS (5 vs 3 days, $\mathrm{P}<0.001$ ) were significantly higher as well in the VTE group. After adjusting for common confounder, VTE was found to be an independent predictor of mortality (OR $=1.596,95 \%$ CI [1.399-1.821], $\mathrm{P}<0.001)$.

Conclusion: In summary, melanoma patients with VTE had higher inpatient mortality, LOS, higher hospital cost, and a higher degree of disability upon discharge.

Keywords: melanoma, venous thromboembolism, VTE, coagulation

\section{Introduction}

Venous thromboembolism (VTE) is the second most major cause of mortality in patients with malignancy. ${ }^{1}$ Statistics collected from patients' registries in the United States and Europe propose that around 20\% of all VTE happens in patients with cancer. $^{2,3}$ This risk is maximized in patients diagnosed with metastatic disease at the initial presentation, especially cancers that are rapidly growing which carries a poor prognosis. ${ }^{4}$ The site of cancer and its histologic subtype plays a major role in the risk of VTE, for instance, pancreatic and brain malignancies are found to have a frequent association with a higher risk of thromboembolism. ${ }^{5}$ Multiple components are deemed to be accountable for the hypercoagulable state in malignancy. It has been demonstrated that continuous expression of Tissue Factor (coagulation factor III) and Cancer Procoagulant (CP) protein by the malignant cells and release of cytokines and microparticles by malignant cells can elicit thrombosis. Additionally, the direct physical contact among malignant cells and healthy cells
Correspondence: Mohammad Abu-Tineh Hamad Medical Corporation, National Center for Cancer Care and Research, HMC, Alrayan Street, Doha, Qatar Email mabutineh@hamad.qa (c) (i) ${ }_{\mathrm{Br}}$ 202I Alhasson et al. This work is published by Dove Medical Press Limited, and licensed under a Creative Commons Attribution License. The full terms of the License are and source are credited. 
can cause a localized platelet aggregation along with clotting activation therefore release of procoagulant cytokines from leukocytes. ${ }^{6}$

Melanoma is the fifth leading cancer in men and women in the United States. It is anticipated that approximately 100,350 new melanomas would be diagnosed in the United States by $2020 .^{7}$ About 6850 people are expected to die of melanoma. ${ }^{7}$ Venous thromboembolism events in cancer patients are well described in literature and notably raises the mortality and morbidity of the cancer population, however, it is still under-reported in melanoma patients. ${ }^{1}$ This probably could be due to the confinement of most melanoma to the superficial layers of the skin rather than being in close connection with the bloodstream compared to other types of cancer. ${ }^{8}$ A retrospective study by Sparsa et al concluded the high incidence of VTE in metastatic stage IV melanoma with prevalence similar to gastrointestinal and pulmonary malignancies. Therefore, this study is designed to describe the prevalence of VTE amidst patients with established diagnosed with melanoma, the patient's demographics, and report the effect of VTE on in-patient outcome, mortality, and hospital length of stay (LOS) in melanoma patients with VTE. The study is operated through data from the Nationwide Inpatient Sample (NIS) database of the Agency of Healthcare Research and Quality (AHRQ).

\section{Methods}

\section{Data Source}

We utilized the AHRQ's NIS database, which was developed as part of the Healthcare Cost and Utilization Project (HCUP). The National (Nationwide) Inpatient Sample (NIS) is the largest publicly available all-payer inpatient care database in the United States, as it contains data seven million hospital stays or more. Its vast sample size is optimum for establishing national and regional estimates and permits analyses of rare conditions, unusual treatments, and special populations. It includes data from approximately 8 million patient hospital stays per year from over 1000 hospitals and is a representative sample of about $20 \%$ of non-federal hospitals in the United States.

\section{Study Population}

We captured the patient's data from 2010 to 2014. All patients who were 18 years or older with a diagnosis of melanoma were identified using the clinical classification software codes (CCS). CCS is a tool that is developed by the agency of healthcare research and quality (AHRQ) for grouping the international classification disease (ICD) code into a manageable number of clinical categories. CCS offers scientists to look at classifications without having to sort through thousands of codes. We used CCSICD9 for codes between 2010 and 2014. We selected patient with melanoma diagnosis (1720 172117221723 17241725172617271728 1729). VTE ICD-9 codes were the following $(451.11,451.19,451.81,451.83,453.40$, $453.41,453.42,453.82,453.84,453.85,453.86$, and 453.87) and PE (PE (ICD-9: 415.11, 415.13, and 415.19)

\section{Patient and Hospital Characteristics}

Data extracted from NIS databases include age, gender, race, metastatic cancer status, hospital region (rural vs urban), hospital teaching status (teaching vs nonteaching), hospital bed size (small, medium, large), length of stay (LOS), total charge (those were adjusted to inflation in reference to 2016). Comorbidities were classified using the Elixhauser comorbidity index. ${ }^{9}$ Discharge status was classified as 1 . Routine discharge (for none to minimal disability) 2. Moderate to severe disability. Moderate to severe disability (defined as any beyond routine home discharge; ranging from short-term stay to skilled nursing facility to death upon discharge).

\section{Outcomes}

Outcome included were the trend of VTE in melanoma patients, demographics, inpatient mortality, LOS, cost of hospitalization, and disability at discharge.

\section{Statistical Analysis}

Data from the Nationwide Inpatient Sample (NIS) database of the Agency of Healthcare Research and Quality (AHRQ) were analyzed. NIS provides the largest all-payer inpatient databases which provide information on roughly $20 \%$ of all US hospital stays. Adults $\geq 18$ years who were admitted to the hospital with melanoma during the period between 2010 and 2014 were identified utilizing the appropriate ICD-9 codes. Patients were sorted based on the absence/ presence of VTE. Demographic characteristics and in-hospital outcomes among Melanoma without and with VTE were compared. Multiple logistic regression was utilized to obtain risk-adjusted odds ratio (OR) to compare inpatient mortality, length of stay (LOS), total charges, and disability at discharge between Melanoma patients with and without VTE. The regression model was modified for sex, melanoma stage, age, race, and presence of comorbid conditions. 


\section{Results}

\section{Baseline Characteristics}

A total of 61,812 melanoma patients were included in our analysis, among them 5.2\% were admitted with a VTE. Mean age in the VTE group was similar 63.3 years vs 63.6 years in the non-VTE group (P-value 0.275). Most patients were white; $90.8 \%$ of the VTE group and $91.2 \%$ of the nonVTE group $(\mathrm{P}<0.01)$. Hispanic were second most common;
$3.9 \%$ in the VTE group. Most patients with VTE had a metastatic melanoma (58.2\%) whereas most patients without VTE had a non-metastatic melanoma (62.8\%), $\mathrm{P}<0.001$.

Most melanoma patients were males and $65.2 \%$ of patients with VTE were males. $66.7 \%$ of VTE group had 3 or more Elixhauser comorbidities Index compared to $53 \%$ in non-VTE group, $\mathrm{P}<0.001$. Patients with VTE were more likely to have coagulopathy $(10.6 \%$ vs $6.9 \%$,

Table I Baseline Characteristics of Melanoma Patients with or Without VTE $(n=6|, 8| 2)$

\begin{tabular}{|c|c|c|c|}
\hline Melanoma Patients & VTE, $\mathbf{n}(\%)$ & No VTE, n (\%) & P-value \\
\hline Overall & $3237(100)$ & $58,575(100)$ & \\
\hline Age (years) mean, SD & $63.3(15.2)$ & $63.6(16)$ & 0.275 \\
\hline $\begin{array}{l}\text { Sex } \\
\qquad \text { Males } \\
\text { Females }\end{array}$ & $\begin{array}{l}2107(65.2) \\
1125(34.8)\end{array}$ & $\begin{array}{l}36,786(62.8) \\
21,767(37.2)\end{array}$ & 0.007 \\
\hline $\begin{array}{l}\text { Race } \\
\text { White } \\
\text { Black } \\
\text { Asian or pacific islander } \\
\text { Native American } \\
\text { Hispanic } \\
\text { Others }\end{array}$ & $\begin{array}{l}2758(90.8) \\
66(2.2) \\
41(1.3) \\
10(0.3) \\
119(3.9) \\
45(1.5)\end{array}$ & $\begin{array}{l}49,552(91.2) \\
1081(2) \\
439(0.8) \\
99(0.2) \\
2232(4.1) \\
927(1.7)\end{array}$ & 0.01 \\
\hline $\begin{array}{l}\text { Melanoma stage } \\
\text { Non-metastatic } \\
\text { Metastatic }\end{array}$ & $\begin{array}{l}\text { I353 (4I.8) } \\
\text { I884 (58.2) }\end{array}$ & $\begin{array}{l}35,013(59.8) \\
23,563(40.2)\end{array}$ & $<0.001$ \\
\hline $\begin{array}{l}\text { Comorbidities } \\
\text { Coagulopathy } \\
\text { Congestive heart failure } \\
\text { Hypertension } \\
\text { Dyslipidemia } \\
\text { Atrial fibrillation } \\
\text { Chronic pulmonary disease } \\
\text { Liver disease } \\
\text { Renal failure } \\
\text { Smoking } \\
\text { Obesity } \\
\text { Alcohol abuse }\end{array}$ & $\begin{array}{l}344(10.6) \\
220(6.8 \%) \\
1563(48.3 \%) \\
867(26.8) \\
430(13.3) \\
428(13.2 \%) \\
55(1.7 \%) \\
246(7.6 \%) \\
755(23.3) \\
334(10.3 \%) \\
50(1.5 \%)\end{array}$ & $\begin{array}{l}4060(6.9) \\
3677(6.3 \%) \\
29,234(49.9 \%) \\
16,644(28.4) \\
797 \mid(13.6) \\
7434(12.7 \%) \\
1063(1.8 \%) \\
5012(8.6 \%) \\
14,976(25.6) \\
4775(8.2 \%) \\
1180(2 \%)\end{array}$ & $\begin{array}{l}<0.00 \mathrm{I} \\
0.234 \\
0.074 \\
0.048 \\
0.615 \\
0.372 \\
0.678 \\
0.062 \\
0.004 \\
<0.001 \\
0.073\end{array}$ \\
\hline $\begin{array}{l}\text { Elixhauser comorbidities Index } \\
0 \\
1 \\
2 \\
3 \text { or more }\end{array}$ & $\begin{array}{l}10(0.3) \\
384(11.9) \\
684(21.1) \\
2159(66.7)\end{array}$ & $\begin{array}{l}3246(5.6) \\
10,908(18.6) \\
13,329(22.8) \\
31,074(53)\end{array}$ & $<0.001$ \\
\hline $\begin{array}{l}\text { Location/teaching status of the hospital } \\
\text { Rural } \\
\text { Urban non-teaching } \\
\text { Urban teaching }\end{array}$ & $\begin{array}{l}251(7.8) \\
879(27.2) \\
2106(65.1)\end{array}$ & $\begin{array}{l}4745(8.1) \\
|5,33|(26.3) \\
38,304(65.6)\end{array}$ & 0.449 \\
\hline
\end{tabular}


$\mathrm{P}<0.001$ ), and obesity (10.3\% vs $8.2 \%, \mathrm{P}<0.001)$, but less likely to have dyslipidemia $(26.8 \%$ vs $28.4 \%, \mathrm{P}=0.048)$ and be smokers $(23.3 \%$ vs $25.6 \%, \mathrm{P}=0.004)$. Other baseline comorbidities including congestive heart failure, hypertension, atrial fibrillation, chronic pulmonary disease, liver disease, renal failure, and alcohol abuse did not differ significantly between the two groups. Table 1 summarizes baseline characteristics in included patients.

\section{Morbidity Outcome}

The presence of VTE was associated with a significantly higher rate of discharge with a moderate to severe disability $(57.5 \%$ vs $41.4 \%, \mathrm{P}<0.001)$, in-hospital stroke $(7.6 \%$ vs $4.9 \%, \mathrm{P}<0.001)$, and in-hospital mortality (8.8\% vs $5.1 \%$, $\mathrm{P}<0.001)$. Costs of hospitalization $(64,720 \$$ vs 46,606 , $\mathrm{P}<0.001$ ) and length of stay (5 vs 3 days, $\mathrm{P}<0.001$ ) were also significantly higher in the VTE group (Table 2).

\section{Mortality Outcome}

After adjustment for age, sex, race, melanoma stage, coagulopathy, congestive heart failure, hypertension, dyslipidemia, atrial fibrillation, chronic pulmonary disease, liver disease, renal failure, smoking, obesity, and alcohol abuse, the presence of VTE was shown to be an independent predictor of mortality $(\mathrm{OR}=1.596$, 95\% CI [1.3991.821], $\mathrm{P}<0.001$ ) (Table 3). Mortality in males is higher compared to females OR 1.38, $\mathrm{p}<0.001$.

\section{Discussion}

Patients with malignancy are at a high risk of venous thromboembolism (VTE), which contributes to morbidity and mortality, playing a significant role in healthcare utilization among oncology patients. ${ }^{10}$ Due to the heterogeneity of cancers, variable incidence of VTE have been reported in patients with cancer, ranging from $0.6 \%$ to $7.8 \%$. $^{11-13}$ Reaching as high as $15 \%$ as observed by Goodnough et al in patients with stage IV breast cancer receiving chemotherapy. ${ }^{14}$ VTE risk in melanoma remains underreported in the literature. ${ }^{15}$ Our study, involving $61,812 \mathrm{mel}-$ anoma patients, is the first comprehensive study to date to examine the prevalence, demographics, hospital outcomes, and mortality in melanoma patients with VTE in the inpatient setting. We limited our inclusion criteria to patients for whom VTE significantly impacted the hospitalization, as evidenced by a VTE code listed in the top three diagnoses.

Approximately, 5.2\% of patients with malignant melanoma in our analysis experienced VTE during hospitalization, this is comparable with the rates reported by previous studies of hospitalized patients with cancer irrespective of their metastatic status; which is reported as $2.0 \%$ to $4.1 \% .^{11,16}$ In regard to baseline characteristics of patients who developed VTE, our study showed that metastatic disease appeared to be more prevalent in the VTE population. This supports the strong association between metastatic stage malignancy and VTE that was shown in previous studies. ${ }^{17}$ Our study found that Patients with malignant melanoma with VTE had higher odds of mortality compared with those without VTE, Identifying VTE independent predictor of mortality regardless of cancer stage and metastatic status.

Other previous studies have shown an increased risk of VTE in women and the African American population. ${ }^{11,18-20}$ In our study, more women and African Americans had VTE than other populations. Most of the patients with VTE were white which is not surprising as fair skin is an independent risk factor for melanoma. ${ }^{21}$

Table 2 Outcomes of Melanoma Patients with or Without VTE $(n=61,812)$

\begin{tabular}{|c|c|c|c|}
\hline Melanoma Patients & VTE, n (\%) & No VTE, n (\%) & P-value \\
\hline Overall & $3237(100)$ & $58,575(100)$ & \\
\hline Discharge type & & & $<0.001$ \\
\hline None to minimal disability & $|37|(42.5)$ & $34,230(58.6)$ & \\
\hline Moderate to severe disability* & $1852(57.5)$ & $24,212(41.4)$ & \\
\hline Cost $(\$)$ mean, SD & $64,720(87,249)$ & $46,606(53,897)$ & $<0.001$ \\
\hline Bleeding & $50(1.5)$ & $684(1.2)$ & 0.062 \\
\hline Stroke & $246(7.6 \%)$ & $2893(4.9 \%)$ & $<0.001$ \\
\hline In-hospital mortality & $286(8.8)$ & $3004(5.1)$ & $<0.001$ \\
\hline Length of stay (days) Median, IQR & $5(3-8)$ & $3(2-6)$ & $<0.001$ \\
\hline
\end{tabular}

Notes: *Moderate to severe disability (defined as any beyond routine home discharge; ranging from short-term stay to skilled nursing facility to death upon discharge). 
Table 3 Multivariate Logistic Regression for Prediction of in-Hospital Mortality in Melanoma Patients

\begin{tabular}{|c|c|c|}
\hline & Odds Ratio (95\% Cl) & P-value \\
\hline The presence of VTE (vs no) & $1.596(1.399-1.821)$ & $<0.001$ \\
\hline Age (in years) & $1.005(1.002-1.008)$ & $<0.001$ \\
\hline Female sex (vs male sex) & $0.728(0.67 I-0.789)$ & $<0.001$ \\
\hline \multicolumn{3}{|l|}{ Race (vs white) } \\
\hline Black & $0.928(0.696-1.236)$ & 0.609 \\
\hline Hispanic & $1.499(1.274-1.764)$ & $<0.001$ \\
\hline Asian or Pacific Islander & $1.413(0.995-2.007)$ & 0.053 \\
\hline Native American & $1.814(0.939-3.506)$ & 0.076 \\
\hline Other races & $1.524(1.195-1.944)$ & 0.001 \\
\hline Metastatic melanoma (vs non-metastatic) & $1.833(1.701-1.976)$ & $<0.001$ \\
\hline Coagulopathy (vs no) & $1.597(1.399-1.821)$ & $<0.001$ \\
\hline Congestive heart failure (vs no) & $1.543(1.353-1.760)$ & $<0.001$ \\
\hline Hypertension (vs no) & $0.770(0.710-0.836)$ & $<0.001$ \\
\hline Dyslipidemia (vs no) & $0.775(0.707-0.850)$ & $<0.001$ \\
\hline Atrial fibrillation (vs no) & $1.417(1.278-1.570)$ & $<0.001$ \\
\hline Chronic pulmonary disease (vs no) & $1.182(1.060-1.319)$ & 0.003 \\
\hline Liver disease (vs no) & $1.807(1.459-2.237)$ & $<0.001$ \\
\hline Renal failure (vs no) & $1.452(1.290-1.635)$ & $<0.001$ \\
\hline Smoking (vs no) & $0.730(0.665-0.800)$ & $<0.001$ \\
\hline Obesity (vs no) & $0.765(0.656-0.892)$ & 0.001 \\
\hline Alcohol abuse (vs no) & $0.580(0.4 \mid 7-0.806)$ & 0.001 \\
\hline
\end{tabular}

We report an increase in hospitalizations, inpatient charges, and overall length of stay in melanoma patients with VTE when compared to melanoma patients without VTE, leading to an overall increase in total healthcare costs $(64,720 \$$ in our VTE cohort). This could be due to the complications of VTE leading to more investigations, treatment, and longer hospital stay. Adding more burdens to the patients and the healthcare system.

The strengths of this analysis include the large sample size used for powered analysis. The study is limited by the cross-sectional study design that does not allow to determine any causality. Second, NIS data lacks information regarding medications; hence, we could not account for the use of VTE prophylaxis and treatment that might have influenced the outcome. The NIS does not provide the cause of the admission rather than it lists the ICD-9 codes of the whole diagnoses of a particular patient both acute and chronic in that hospital stay. The NIS does not distinguish patients with multiple admissions, because it is based on unique admission rather than a unique patient. Therefore, it is possible that repeated admissions of the same patients were included, and thereby VTE rates were underestimated or overestimated.

\section{Conclusion}

Our study identifies VTE as a significant complication of malignant melanoma that exerts a considerable negative impact on patient outcomes and overall healthcare costs. Given that some VTEs are preventable, there may be a need for more strict compliance with prevention methods in the high-risk patient population. As some of previous surveys showed only $52 \%$ of the hospitalized patient with a high risk of VTE are receiving appropriate prophylaxis. $^{22}$ Our study highlights the need for more prospective studies to clarify the impact of VTE in malignant melanoma patients and identify effective strategies to improve the outcome observed in this population.

\section{Acknowledgment}

We thank Qatar National library for funding this article

\section{Author Contributions}

All authors contributed to drafting or revising the article, have agreed on the journal to which the article will be submitted, gave final approval to the version to be published, and agree to be accountable for all aspects of the work. 


\section{Disclosure}

None of the authors declared a conflict of interest.

\section{References}

1. Mullard A, Innes H. Venous thromboembolism in malignancy. Clin Med. 2014;14(5):532-534. doi:10.7861/clinmedicine.14-5-532

2. Heit JA, O'Fallon WM, Petterson TM, et al. Relative impact of risk factors for deep vein thrombosis and pulmonary embolism: a population-based study. Arch Intern Med. 2002;162(11):1245-1248. doi:10.1001/archinte.162.11.1245

3. Imberti D, Agnelli G, Ageno W, et al. Clinical characteristics and management of cancer-associated acute venous thromboembolism: findings from the MASTER Registry. Haematologica. 2008;93 (2):273-278. doi:10.3324/haematol.11458

4. Wun T, White RH. Epidemiology of cancer-related venous thromboembolism. Best Pract Res Clin Haematol. 2009;22(1):9-23. doi:10.1016/j.beha.2008.12.001

5. Schmaier AA, Ambesh P, Campia U. Venous thromboembolism and cancer. Curr Cardiol Rep. 2018;20(10):89. doi:10.1007/s11886-0181034-3

6. Falanga A, Marchetti M, Russo L. The mechanisms of cancer-associated thrombosis. Thromb Res. 2015;135:S8-11. doi:10.1016/S0049-3848(15) 50432-5

7. Cancer facts and figures; 2019. Available from: https://www.cancer. org/research/cancer-facts-statistics/all-cancer-facts-figures/cancerfacts-figures-2019.html. Accessed October 29, 2021.

8. Roland CL, Ross MI, Hall CS, et al. Detection of circulating melanoma cells in the blood of melanoma patients: a preliminary study. Melanoma Res. 2015;25(4):335-341. doi:10.1097/CMR.0000000000000168

9. Elixhauser A, Steiner C, Harris DR, Coffey RM. Comorbidity measures for use with administrative data. Med Care. 1998;36:8-27. doi:10.1097/00005650-199801000-00004

10. Sorensen HT, Mellemkjaer L, Olsen JH, Baron JA. Prognosis of cancers associated with venous thromboembolism. $N$ Engl J Med. 2000;343:1846-1850. doi:10.1056/NEJM200012213432504

11. Khorana AA, Francis CW, Culakova E, et al. Frequency, risk factors, and trends for venous thromboembolism among hospitalized cancer patients. Cancer. 2007;110:2339-2346. doi:10.1002/cncr.23062
12. Levitan N, Dowlati A, Remick SC, et al. Rates of initial and recurrent thromboembolic disease among patients with malignancy versus those without malignancy risk analysis using medicare claims data. Medicine. 1999;78:285-291.

13. Sallah S, Wan JY, Nguyen NP. Venous thrombosis in patients with solid tumors: determination. Thrombosis Haemostasis. 87 (4):575-579.

14. Scates SM. Diagnosis and treatment of cancer-related thrombosis. Semin Thromb Hemost. 1992;18:373-379.

15. Sparsa A, Durox H, Doffoel-Hantz V, et al. High prevalence and risk factors of thromboembolism in stage IV melanoma. J Eur Acad Dermatol Venereol. 2011;25(3):340-344. doi:10.1111/j.14683083.2010.03795.x

16. Stein PD, Beemath A, Meyers FA, et al. Incidence of venous thromboembolism in patients hospitalized with cancer. $\mathrm{Am} \mathrm{J} \mathrm{Med.}$ 2006;119:60-68. doi:10.1016/j.amjmed.2005.06.058

17. Mohammed KA, Kahee A, Hinyard L, et al. Description of venous thromboembolism in hospitalized patients with metastatic cancer: a national sample. J Nat Compr Cancer Network. 2018;16 (2):136-143. doi:10.6004/jnccn.2017.7037

18. Streiff MB. Association between cancer types, cancer treatments, and venous thromboembolism in medical oncology patients. Clin Adv Hematol Oncol. 2013;11:349-357.

19. White RH, Zhou H, Romano PS. Incidence of idiopathic deep venous thrombosis and secondary thromboembolism among ethnic groups in California. Ann Intern Med. 1998;128(9):737-740. doi:10.7326/ 0003-4819-128-9-199805010-00006

20. Zakai NA, McClure LA. Racial differences in venous thromboembolism. J Thromb Haemost. 2011;9(10):1877-1882. doi:10.1111/j.1538-7836.2011.04443.x

21. Bradford PT. Skin cancer in skin of color. Dermatol Nurs. 2009;21 (4):170-178.

22. Rothberg MB, Lahti M, Pekow PS, Lindenauer PK. Venous thromboembolism prophylaxis among medical patients at US hospitals. J Gen Intern Med. 2010;25(6):489-494. doi:10.1007/s11606-0101296-y
International Journal of General Medicine

\section{Publish your work in this journal}

The International Journal of General Medicine is an international, peer-reviewed open-access journal that focuses on general and internal medicine, pathogenesis, epidemiology, diagnosis, monitoring and treatment protocols. The journal is characterized by the rapid reporting of reviews, original research and clinical studies across all disease areas. The manuscript management system is completely online and includes a very quick and fair peer-review system, which is all easy to use. Visit http://www.dovepress.com/ testimonials.php to read real quotes from published authors. 